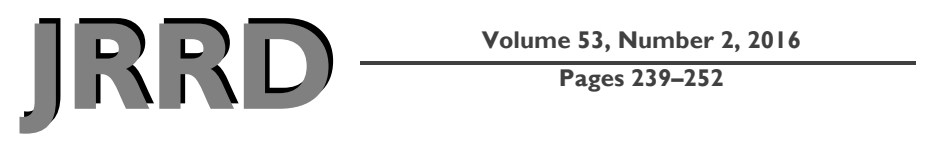

\title{
Patient perspectives on virtual reality-based rehabilitation after knee surgery: Importance of level of difficulty
}

\author{
Minyoung Lee, PT, BSc; ${ }^{1}$ Dongwon Suh, MD, PhD; ${ }^{2}$ Jaebum Son, PhD; $^{3}$ Jungjin Kim, PT, MS; $^{1}$ Seon-Deok Eun, \\ PhD; ${ }^{4}$ BumChul Yoon, PT, OT, PhD ${ }^{1^{*}}$ \\ ${ }^{1}$ Department of Physical Therapy, College of Health Science; and Rehabilitation Science, Department of Health Science, \\ Graduate School, Korea University, Seoul, South Korea; ${ }^{2}$ Barunsesang Hospital, Seongnam, South Korea; ${ }^{3}$ Department \\ of Biomedical Engineering, University of Los Andes, Bogotá, Colombia; ${ }^{4}$ Korea National Rehabilitation Research Insti- \\ tute, Seoul, South Korea
}

\begin{abstract}
This article explored the perspectives of 25 patients regarding virtual reality (VR)-based rehabilitation following knee surgery and identified the important factors that allowed patients to immerse themselves in rehabilitation. Qualitative analysis of data collected via open-ended questionnaire and quantitative analysis of data from physical assessments and surveys were conducted. In the open-ended questionnaire, the majority of participants mentioned level of difficulty as the most common reason for selecting both the most and the least immersive exercise programs. Quantitative analysis showed that participants experienced a high level of flow $(3.9+/-0.3$ out of 5.0) and a high rate of expectation of therapeutic effect $(96 \%)$ and intention of exercise adherence (96\%). Further, participants with more severe pain or physical dysfunction tended to have more positive experiences (e.g., Difficulty-Skill Balance, Clear Goals, and Transformation of Time), leading to high levels of flow during VR-based rehabilitation. In conclusion, VR-based games are potentially acceptable as a motivational rehabilitation tool for patients following knee surgery. However, to best meet patients' needs, it might be useful to equip a VR program with varied levels of difficulty, taking into account the severity of the individual's knee injury. Additionally, severe pain or physical dysfunction might act as an indication rather than a contraindication for VR-based rehabilitation.
\end{abstract}

Key words: flow experience, knee injury, level of difficulty, motivation, pain, patient perspectives, physical function, physical therapy, rehabilitation, virtual reality.

\section{INTRODUCTION}

Virtual reality (VR)-based games are a highly immersive form of interactive media, incorporating clear goals and immediate feedback [1-2]. Because of such characteristics, many researchers have tried to use VR-based games as a rehabilitation tool for patients with neurological [3-6] and musculoskeletal [7] conditions and burn injuries [8-10]. Recently, the Nintendo Wii Fit Plus (NWFP) was evaluated as an adjunct to conventional physical therapy for outpatients following total knee replacement, and it showed similar effects as conventional physical therapy in improving lower-limb and balance outcomes [11].

\footnotetext{
Abbreviations: $\mathrm{ABC}=$ Activity-Specific Balance Confidence (scale), $\mathrm{COP}=$ center of pressure, FSS-2 = Flow State Scale-2, KUUEQ $=$ Korea University User Experience Questionnaire, LEFS $=$ Lower Extremity Functional Scale, NPRS = numerical pain rating scale, NWFP $=$ Nintendo Wii Fit Plus, $\mathrm{PT}=$ physical therapist, $\mathrm{ROM}=$ range of motion, $\mathrm{SLS}=$ Single-Leg Stance, $\mathrm{VR}=$ virtual reality.

*Address all correspondence to BumChul Yoon, PT, OT, PhD; Department of Physical Therapy, College of Health Sciences, Korea University 145, Anam-ro, Sungbuk-gu, Seoul 136-701, Republic of Korea. Email: yoonbc@korea.ac.kr http://dx/doi.org/10.1682/JRRD.2014.07.0164
} 
However, the overriding rationale for the use of VRbased rehabilitation is its ability to provide engaging and enjoyable environments [12-13]. Thus, exploring patient perspectives regarding VR-based rehabilitation is a possible next step in informing ways to motivate patients, thereby potentially leading to greater participation and improved outcomes [14-15].

At present, only the perspectives of patients with neurological conditions regarding VR-based rehabilitation have been explored [16-21], whereas few studies have examined the perspectives of patients with musculoskeletal conditions regarding VR-based rehabilitation. Musculoskeletal conditions are the most common reason for long-term pain and physical disability, causing 54 percent of all long-term disability and 24 percent of all restricted activity days [22-23], and regular exercise participation is reported to be important for the treatment of these musculoskeletal conditions [24]. Considering such a high prevalence rate and the importance of continuous exercise, it is therefore meaningful to examine the perspectives of patients with musculoskeletal conditions regarding VR-based rehabilitation to determine whether and how VR can be adopted as a motivating rehabilitation tool.

One of the main perceptions that people report while being highly engaged in VR-based games is called "flow experience" [25]. Csikszentmihalyi defined flow as "the state in which people are so involved in an activity that nothing else seems to matter; the experience itself is so enjoyable that people will do it even at great cost, for the sheer sake of doing it" and identified nine dimensions of flow experience through numerous in-depth interviews with people in various fields [25]. Jackson and Marsh designed a survey, the Flow State Scale-2 (FSS-2), to assess these nine dimensions of flow experience quantitatively [26]. Specifically, the nine FSS-2 dimensions are (1) Difficulty-Skill Balance, (2) Merging of Action and Awareness, (3) Clear Goals, (4) Unambiguous Feedback, (5) Concentration on Task at Hand, (6) Sense of Control, (7) Loss of Self-Consciousness, (8) Transformation of Time, and (9) Autotelic Experience. The FSS-2 has been extensively validated [27-28] and is widely used to assess people's flow experience during sports [28-29] and games [30-31].

The aim of this study was to explore the perspectives of knee surgery patients regarding VR-based rehabilitation. For this purpose, we adopted a mixed-methods approach using both qualitative and quantitative analysis [32-33]. For qualitative analysis, we explored patients' subjective reasons for flow experience in VR-based rehabilitation. For quantitative analysis, we had two hypotheses. First, we hypothesized that there would be a negative relationship between the severity of the knee injury and the level of flow experience. Second, we hypothesized that the level of flow experience while patients engaged in VR-based rehabilitation would be lower than the published norm values of flow experience that have been established for sports, physical activity, and dance in nondisabled participants.

\section{METHODS}

\section{Participants}

This study was conducted in a joint rehabilitation center in Barunsesang Hospital, Seongnam, South Korea. Researchers advertised information about the study on a message board at the joint rehabilitation center for 2 mo to recruit participants. Participants who underwent surgical operation (e.g., total knee replacement arthroplasty, surgical repair, or partial meniscectomy) on the knee joint were recruited. A total of 29 volunteers were assessed for eligibility, and 4 individuals were excluded from the study for the following reasons: private schedule $(n=2)$ and not meeting the inclusion criteria $(n=2)$; therefore, 25 participants were enrolled in the study. Participants were included in the study if more than $4 \mathrm{wk}$ had passed since their operation, if they could stand independently, if they had normal cognition (Mini-Mental State Examination score $>25$ [34]), and if they had unimpaired comprehension and could follow instructions. Participants were excluded if they had a history of epilepsy or currently used a pacemaker.

\section{Equipment}

\section{Hardware}

Hardware included a Nintendo Wii (RVL-001, Nintendo of Korea; Seoul, South Korea), a force sensor called the Balance Board (RVL-021, Nintendo of Korea), and a 50 in. plasma display panel monitor (50PA4500NM, LG Electronics Co; Gumi-si, South Korea). The participant's movements on the Balance Board were reflected in an avatar that appeared on the monitor. The Nintendo Wii receives information on the individual's center of pressure (COP) from the Balance Board (which has been reported as a valid tool for assessing standing 
balance [35]) and provides it to the participant via the monitor. Thus, when the participants move on the Balance Board, they are able to see their movement via the avatar and get real-time visual and auditory feedback of their COP.

\section{Software}

In NWFP (RVL-006, Nintendo of Korea), VR game contents were chosen following discussion between researchers, an orthopedic surgeon, and physical therapists (PTs) in a joint rehabilitation center. The NWFP was validated for its effects on the lower limbs and balance in patients following knee surgery by Fung et al., although participant perspectives regarding NWFP were not identified [11]. Three categories of game content and eight sessions were selected because they included exercises similar to those that had been conducted in a rehabilitation center for patients following knee surgery: (1) yoga content: Palm Tree and Warrior sessions; (2) strength training content: Balance Bridge and Single-Leg Extension sessions; and (3) balance games content: Ski Slalom, Tightrope Walk, Penguin Slide, and Table Tilt sessions.
Table 1 shows detailed descriptions of each session, and Figure 1 shows examples of the participant's movements while engaging in the VR-based rehabilitation.

For yoga and strength training, the participant exercised while guided by a trainer who appeared on the monitor (i.e., training type), whereas during balance games, the participant exercised without a trainer (i.e., game type). During yoga and strength training, the trainer guided the participant toward more exact movements with visual and auditory feedback. A red dot, indicating the participant's COP, was displayed on the monitor, and the trainer instructed the participant to remain within the yellow circle to maintain the correct posture (Figure 1(a)-(b)). In balance games, the participant conducted agility and static and dynamic balance training in virtual environments, and a real-time score was seen on the screen while the participant completed the games (Figure 1(c)-(d)). Balance games content varied in level of difficulty (e.g., beginning and advanced), whereas yoga and strength training content had only one level. After each session, the software provided participants with their skill level and rank information.

Table 1.

Detailed descriptions of each virtual reality-based rehabilitation session.

\begin{tabular}{|c|c|c|}
\hline Content & Session & Detailed Description \\
\hline \multirow[t]{2}{*}{ 1: Yoga (training type) } & Palm Tree & $\begin{array}{l}\text { This exercise required participants to stand on the board and rise up on their toes. } \\
\text { Participants were asked to move both arms back and keep their backs straight. }\end{array}$ \\
\hline & Warrior & $\begin{array}{l}\text { Participants were asked to align their heels with each other, with one leg on the } \\
\text { board and the other leg straightened behind the board. Participants flexed the } \\
\text { knee of the foot on the board, positioning their center of pressure on the center } \\
\text { of their body. }\end{array}$ \\
\hline \multirow[t]{2}{*}{$\begin{array}{l}\text { 2: Strength Training } \\
\text { (training type) }\end{array}$} & Balance Bridge & $\begin{array}{l}\text { Participants raised their hips in a supine position and extended one leg out in } \\
\text { front of them, maintaining another leg flexed at } 90^{\circ} \text { for } 6 \text { repetitions. }\end{array}$ \\
\hline & Single-Leg Extension & $\begin{array}{l}\text { Participants raised and extended a straight leg and moved the ipsilateral upper } \\
\text { limb in the opposite direction (as when walking) for } 6 \text { repetitions. }\end{array}$ \\
\hline \multirow[t]{4}{*}{$\begin{array}{l}\text { 3: Balance Games } \\
\text { (game type) }\end{array}$} & Ski Slalom & $\begin{array}{l}\text { Participants leaned left and right on the Balance Board to go through a series of } \\
\text { gates between two flags. }\end{array}$ \\
\hline & Tightrope Walk & $\begin{array}{l}\text { Participants kept their balance on the Balance Board so that the avatar on the } \\
\text { screen did not fall from the rope. }\end{array}$ \\
\hline & Penguin Slide & $\begin{array}{l}\text { Participants leaned left and right on the Balance Board so that an iceberg tilted } \\
\text { depending on the pressure on the board and then caught fish on the iceberg. }\end{array}$ \\
\hline & Table Tilt & $\begin{array}{l}\text { Participants provided pressure in each direction on the Balance Board so that a } \\
\text { platform on the screen tilted in that direction and then rolled a ball into a hole } \\
\text { located in the platform. }\end{array}$ \\
\hline
\end{tabular}



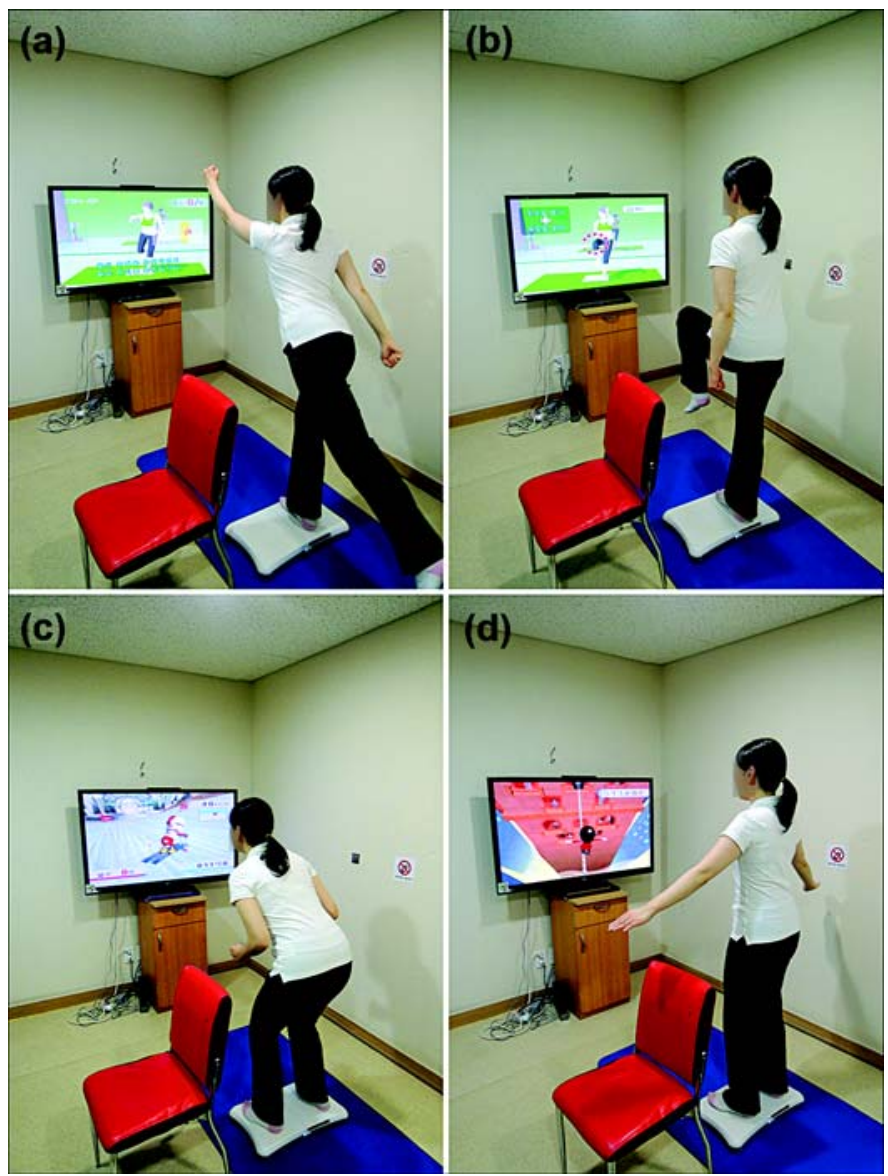

Figure 1.

Examples of participant's movements while engaging in virtual reality-based rehabilitation: (a) hip and knee extension in Single-Leg Extension, (b) hip and knee flexion in Single-Leg Extension, (c) weight shifting side to side with hip and knee flexion in Ski Slalom, and (d) keeping balance in Tightrope Walk.

\section{Measurements}

Pretreatment assessment involved evaluation of the participant's knee pain and physical dysfunction. Posttreatment assessment involved evaluation of the flow experience and user experience after all sessions.

\section{Pretreatment Assessment}

For assessing knee pain and physical dysfunction, we used numerical pain rating scales (NPRSs) [36], the Lower Extremity Functional Scale (LEFS) [37], the ActivitySpecific Balance Confidence scale (ABC) [38], the SingleLeg Stance (SLS) [39-40], a digital inclinometer (Acumar OC-3053-02, OrthoCanada; Ottawa, Canada) [41-43], and a digital handheld dynamometer (MicroFET2, Hoggan
Health Industries Inc; Salt Lake City, Utah) [44-46]. Details on the objectives for each measurement are described in Table 2.

\section{Posttreatment Assessment}

The FSS-2 was used to assess flow experience within a particular event or activity, theoretically grounded in Csikszentmihalyi's nine dimensions [25]. Each dimension of the FSS-2 is composed of 4 items, resulting in a total of 36 items [26]. The nine dimensions of the FSS-2 and examples of items for each dimension are shown in Table 3. Participants chose appropriate answers on a 5-point Likert scale $(1=$ totally disagree; $5=$ totally agree $)$ for each of the 36 items. Each score of the nine dimensions and the total FSS-2 score were calculated based on the published manual [28]. The FSS-2 has been validated extensively in the sport and physical activity settings [2728]. For this study, the FSS- 2 was translated into Korean [47]. Cronbach $\alpha$ for all translated questions for the nine dimensions have been shown to exceed 0.61 [47].

The Korea University User Experience Questionnaire (KUUEQ) was self-designed by our research team, including a PT and an orthopedic surgeon, both with more than $10 \mathrm{yr}$ clinical experience. The questionnaire contained two closed-ended questions that asked in which sessions the participant experienced flow the most and the least and two open-ended questions on the reasons the participant chose these sessions. It also contained two closed-ended questions on whether the participants thought that there would be any physical improvement if they continued this VR-based rehabilitation and whether they would like to use the NWFP for rehabilitation at home or in the hospital in the future (Figure 2).

\section{Procedure}

Two PTs with more than $5 \mathrm{yr}$ clinical experience conducted pretreatment assessments to evaluate participants' pain and physical dysfunction. After assessment, each participant was introduced to the VR game system. Each of the eight sessions lasted for about $2.5 \mathrm{~min}$. Thus, the total duration of the exercise program was about $30 \mathrm{~min}$, including warm-up and cool-down exercises and a $1 \mathrm{~min}$ rest offered between each session. The order of contents was planned using an online random number generator for every participant. A therapist stood by for assistance during all treatment time. If the participants could not play the games with their full range of motion (ROM), 
Table 2.

Objectives and details of pretreatment assessment measurements.

\begin{tabular}{|c|c|c|}
\hline Measurement & $\begin{array}{l}\text { Measurement } \\
\text { Objective }\end{array}$ & Measurement Details \\
\hline $\begin{array}{l}\text { Numerical Pain Rating } \\
\text { Scale }\end{array}$ & Pain level & 11-point self-reported scale $(0=$ no pain at all to $10=$ worst possible pain $)$. \\
\hline $\begin{array}{l}\text { Lower Extremity } \\
\text { Functional Scale }\end{array}$ & $\begin{array}{l}\text { Lower-limb functional } \\
\text { condition }\end{array}$ & $\begin{array}{l}20 \text { questions scored using 5-point Likert scale }(0=\text { extremely difficult to } 4=\text { not } \\
\text { difficult at all); final scores were summed. }\end{array}$ \\
\hline $\begin{array}{l}\text { Activity-Specific Bal- } \\
\text { ance Confidence Scale }\end{array}$ & $\begin{array}{l}\text { Confidence in activity- } \\
\text { specific balance }\end{array}$ & $\begin{array}{l}\text { 16-item scale, scored from } 0 \text { to } 100(0=\text { not at all confident to } 100=\text { fully confi- } \\
\text { dent }) \text {; final summed scores were converted to percentages. }\end{array}$ \\
\hline Single-Leg Stance & Balance & $\begin{array}{l}\text { Participants were asked to stand on affected leg as long as possible for } 30 \mathrm{~s} \text {, with } \\
\text { eyes both closed and open. }\end{array}$ \\
\hline $\begin{array}{l}\text { Hip and Knee Range of } \\
\text { Motion }\end{array}$ & Range of motion & $\begin{array}{l}\text { Digital inclinometers }{ }^{*} \text { were applied to } 5 \text { hip and knee joints of affected leg to } \\
\text { measure hip flexion in supine position, hip adduction and abduction in side- } \\
\text { lying position, hip extension in prone position, and knee flexion at } 90^{\circ} \text { in sit- } \\
\text { ting position. Mean value for } 3 \text { trials was calculated for each motion. }\end{array}$ \\
\hline $\begin{array}{l}\text { Hip and Knee Muscle } \\
\text { Strength }\end{array}$ & $\begin{array}{l}\text { Maximum voluntary } \\
\text { isometric strength }\end{array}$ & $\begin{array}{l}\text { Digital dynamometer }{ }^{\dagger} \text { was applied to } 6 \text { hip and knee muscle groups of affected leg } \\
\text { to measure hip flexion in supine position, hip adduction and abduction in side- } \\
\text { lying position, hip extension in prone position, and knee flexion and extension at } \\
90^{\circ} \text { in sitting position. Mean value for } 3 \text { trials was calculated for each motion. }\end{array}$ \\
\hline
\end{tabular}

Table 3.

Descriptions and examples of questions on nine dimensions of Flow State Scale-2. Dimension, description of dimension, and example of question were adapted from Jackson and Marsh [26].

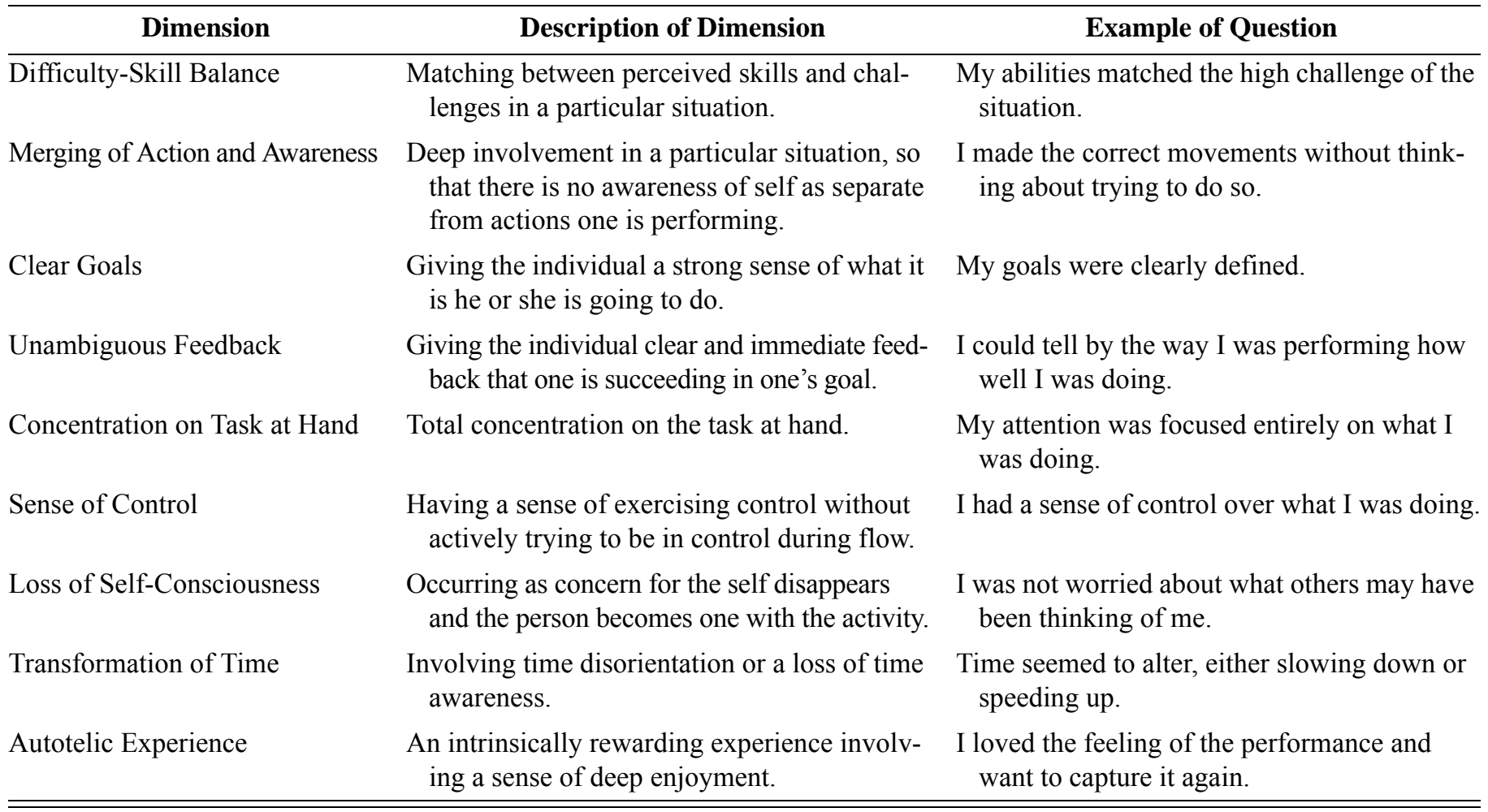


1. In which session among the eight ${ }^{*}$ did you experience flow the most? ${ }^{\dagger}$

2. What is the reason you experienced flow the most in the session you selected in question 1 ? $^{\ddagger}$

3. In which session among the eight ${ }^{*}$ did you experience flow the least? ${ }^{+}$

4. What is the reason you experienced flow the least in the session you selected in question $3 ?^{\ddagger}$

5. Do you think that there will be any physical improvement if you do these exercise sessions? Yes or $\mathrm{No}^{+}$

6. From what type of program do you expect physical improvement? Both types, only training type, only game type ${ }^{\dagger}$

7. Would you like to use the NWFP in future treatments for rehabilitation at home or in hospital? Yes or $\mathrm{No}^{+}$

Figure 2.

Contents of Korea University User Experience Questionnaire (KUUEQ). Note: KUUEQ was self-designed by research team of current study. "Eight sessions were Palm Tree, Warrior, Balance Bridge, Single-Leg Extension, Ski Slalom, Tightrope Walk, Penguin Slide, and Table Tilt from Nintendo Wii Fit Plus (NWFP) (RVL-006, Nintendo of Korea; Seoul, South Korea). ${ }^{\dagger}$ Closed-ended question. ${ }^{\ddagger}$ Open-ended question.

the therapist instructed them to modify their posture, allowing them to play the games with limited ROM. When the participants expressed discomfort even with limited ROM, they were allowed to hold onto a highbacked chair that was placed beside them. After finishing all sessions, participants conducted posttreatment assessment, including the FSS-2 and the KUUEQ. Participants were asked to respond verbally to the open-ended questions of the KUUEQ, and all verbal responses were recorded.

\section{Data Analysis}

A content analysis approach was used to analyze the responses of the open-ended questions of the KUUEQ [48]. All audio of recorded responses was fully transcribed word-for-word to strengthen the trustworthiness of the qualitative data by avoiding the selective recording of responses [49]. To increase the credibility of the study, two researchers, who were certified PTs, independently coded full transcriptions by sentence and categorized the codes into themes based on key words that were commonly mentioned throughout the responses [50]. Finally, the resulting themes and sorted codes by theme were presented and discussed with all research team members. We then revised the themes and sorted the codes based on the results of the research team's discussion. Upon completing the analysis of the responses, we presented the results to the participants to verify whether the results corresponded to their intentions [51].

Statistical analysis was performed using SPSS 12.0 (IBM; Armonk, New York). The Spearman rank-order correlation coefficient was used to examine the relation- ship between the total FSS-2 score and NPRS scores, LEFS scores, ABC scores, SLS (with eyes closed and eyes open) times, hip and knee angles, hip and knee muscle strength, and age (the FSS-2 variables were not normally distributed). Additionally, the relationship between each of the nine dimensions of the FSS-2 and the severity of knee pain, physical dysfunction, and age was also examined. We considered correlation coefficients of $r \geq 0.04$ as fairly positive correlation and $r \leq-0.04$ as fairly negative correlation. We use a one-sample $t$-test to compare the FSS-2 mean scores for the sum and for each of the nine dimensions of the current study with the published norm values that have been established for sports, physical activity, and dance for nondisabled participants [28]. Significance was set at $p<0.05$.

\section{RESULTS}

All 25 participants completed the experiment without any dropout. Demographic characteristics and medical diagnoses of participants are shown in Table 4. Overall measurement results of participants' pain and physical dysfunction are summarized in Table 5.

\section{Experience of Flow}

Level of difficulty was the most common reason for selecting the session in which participants experienced flow the most and least. The session in which participants experienced flow the most was Table Tilt $(n=11)$, followed by Tightrope Walk $(n=4)$, Balance Bridge $(n=3)$, Warrior $(n=3)$, Ski Slalom $(n=2)$, Single-Leg Extension $(n=1)$, 
Table 4.

Demographic characteristics and medical diagnoses of participants.

\begin{tabular}{lc}
\hline \multicolumn{1}{c}{ Characteristic } & $\begin{array}{c}\text { Mean } \pm \text { SD } \\
\text { or } \boldsymbol{n}(\%)\end{array}$ \\
\hline $\begin{array}{l}\text { Demographic } \\
\text { Age, yr }\end{array}$ & $36.4 \pm 14.8$ \\
Sex & \\
$\quad$ Male & $11(44)$ \\
$\quad$ Female & $14(56)$ \\
Body Mass Index, kg/m ${ }^{2}$ & $22.87 \pm 2.68$ \\
Length of Outpatient Rehabilitation, d & $28.0 \pm 32.6$ \\
Medical Diagnosis & \\
Anterior Cruciate Ligament Rupture & $15(60)$ \\
Posterior Cruciate Ligament Rupture & $1(4)$ \\
Medial Meniscus Tear & $5(20)$ \\
Lateral Meniscus Tear & $2(8)$ \\
Patellar Dislocation & $2(8)$ \\
\hline SD = standard deviation. & \\
\hline \hline
\end{tabular}

and Penguin Slide $(n=1)$. Six themes emerged as reasons for participants choosing these sessions: correct level of difficulty $(n=7)$, clear goals $(n=6)$, concentration $(n=5)$, enjoyment $(n=5)$, beneficial effects of exercise $(n=3)$, and immediate feedback $(n=1)$.

The session selected as least immersive was Palm Tree $(n=7)$, followed by Single-Leg Extension $(n=4)$, Ski Slalom $(n=4)$, Tightrope Walk $(n=4)$, Balance Bridge $(n=3)$, Penguin Slide $(n=1)$, Warrior $(n=1)$, and Table Tilt $(n=1)$. Seven themes emerged as reasons for participants choosing these sessions: inadequate level of difficulty $(n=16)$, pain $(n=3)$, lack of concentration $(n=2)$, lack of enjoyment $(n=2)$, lack of a sense of unity with virtual characters $(n=2)$, decreased physical function $(n=1)$, and unclear goals $(n=1)$. All of the themes that emerged as reasons for participants experiencing flow the most and least are summarized in Table 6 with representative responses.

\section{Correlation between Flow State Scale-2 Scores and Physical Dysfunction}

There was no significant correlation between total FSS-2 scores and knee pain severity, physical dysfunction, or age. However, some individual dimensions showed significant correlation with these characteristics. For example, the older the participants, the more they experienced an altered sense of time (Figure 3(a)), and sharper pain caused participants to recognize clearer goals (Figure 3(b)). The more lower-limb function and balance declined, the more participants experienced an
Table 5.

Pain and physical function measurements.

\begin{tabular}{lc}
\hline \multicolumn{1}{c}{ Item } & Mean \pm SD \\
\hline Numerical Pain Rating Scale $^{*}$ & $3.04 \pm 1.67$ \\
Lower Extremity Functional Scale $^{\dagger}$ & $53.84 \pm 17.76$ \\
Activity-Specific Balance Confidence Scale $^{\ddagger}$ & $85.08 \pm 13.73$ \\
Single-Leg Stance (s) & \\
With Eyes Open & $26.41 \pm 8.40$ \\
With Eyes Closed & $8.14 \pm 7.70$ \\
Active Range of Motion $\left(^{\circ}\right)$ & \\
Hip Flexion & $110.94 \pm 11.56$ \\
Hip Adduction & $26.64 \pm 9.62$ \\
Hip Abduction & $55.04 \pm 16.05$ \\
Hip Extension & $30.08 \pm 10.20$ \\
Knee Flexion & $107.54 \pm 20.72$ \\
Muscle Strength $(\mathrm{N})$ & \\
Hip Flexion & $17.15 \pm 2.81$ \\
Hip Extension & $17.21 \pm 3.41$ \\
Hip Abduction & $15.07 \pm 3.33$ \\
Hip Adduction & $16.41 \pm 3.07$ \\
Knee Flexion & $14.08 \pm 2.57$ \\
Knee Extension & $14.02 \pm 2.35$ \\
\hline${ }^{*} 0=$ no pain at all to $10=$ worst possible pain. & \\
${ }^{\dagger} 0=$ lowest function to $80=$ highest function. & \\
${ }^{\ddagger} 0=$ not at all confident in activity-specific balance to $100=$ fully confident. \\
SD = standard deviation. & \\
\hline \hline
\end{tabular}

altered sense of time (Figure 3(c)-(d)). The more limited participants' hip-flexion angle, the more they felt that exercise difficulty matched their skill level (Figure 3(e)), and weaker hip adduction muscle strength caused participants to recognize clearer goals (Figure 3(f)). Meanwhile, $\mathrm{ABC}$ scores showed a low negative correlation with the Transformation of Time dimension score, but this correlation was not significant $(p=0.06)$.

\section{Comparison with Norm Values of Flow State Scale-2 Scores}

The total FSS-2 score was significantly higher than the norm value for dance for nondisabled participants $(p<$ $0.001)$. The comparison of the mean score for six of the nine FSS-2 dimensions to norm values is as follows: for Merging of Action and Awareness, the mean score was significantly higher than the norm value for dance $(p<$ 0.05); for Clear Goals, the mean score was significantly higher than the norm value for dance $(p<0.05)$; for Concentration on the Task at Hand, the mean score was significantly higher than the norm value for sports $(p<0.001)$, exercise activity $(p<0.001)$, and dance $(p<0.05)$; for Loss 
JRRD, Volume 53, Number 2, 2016

Table 6.

Emerging themes in participant opinions regarding virtual reality-based rehabilitation exercises.

\begin{tabular}{|c|c|c|}
\hline $\begin{array}{l}\text { Interview } \\
\text { Question }\end{array}$ & Theme & Representative Response (games content) \\
\hline \multirow[t]{6}{*}{$\begin{array}{l}\text { Reasons for Great- } \\
\text { est Flow }\end{array}$} & $\begin{array}{l}\text { Correct level of } \\
\text { difficulty }\end{array}$ & "The level of challenge was suitable for me, so I got a good score." (Warrior) \\
\hline & Clear goals & $\begin{array}{l}\text { "Having the specific goal of putting the ball in the hole made me interested in the game." } \\
\text { (Table Tilt) }\end{array}$ \\
\hline & Concentration & $\begin{array}{l}\text { "The pose involved in performing the exercise helped me concentrate on the exercise." } \\
\text { (Palm Tree) }\end{array}$ \\
\hline & Enjoyment & "The game content made it enjoyable." (Table Tilt) \\
\hline & $\begin{array}{l}\text { Beneficial effects of } \\
\text { exercise }\end{array}$ & $\begin{array}{l}\text { "I thought 'Balance Bridge' would have a great effect on rehabilitation.” (Balance } \\
\text { Bridge) }\end{array}$ \\
\hline & Immediate feedback & $\begin{array}{l}\text { "The rope swayed from side to side whenever I lost my balance and the virtual character } \\
\text { even fell off the rope. This immediate response made me immersed in the game." } \\
\text { (Tightrope Walk) }\end{array}$ \\
\hline \multirow[t]{7}{*}{$\begin{array}{l}\text { Reasons for Least } \\
\text { Flow }\end{array}$} & $\begin{array}{l}\text { Inadequate level of } \\
\text { difficulty }\end{array}$ & "I found it difficult to understand how to perform this exercise." (Tightrope Walk) \\
\hline & Pain & $\begin{array}{l}\text { "I could not comfortably perform the exercise because I could not balance because of the } \\
\text { pain." (Single-Leg Extension) }\end{array}$ \\
\hline & $\begin{array}{l}\text { Lack of } \\
\text { concentration }\end{array}$ & "I concentrated less on this exercise compared with the other ones." (Ski Slalom) \\
\hline & Lack of enjoyment & "I felt this exercise did not suit me at all because I did not enjoy it." (Balance Bridge) \\
\hline & $\begin{array}{l}\text { Decreased physical } \\
\text { function }\end{array}$ & $\begin{array}{l}\text { "I could not put any weight on my ankle, so I moved only my upper body. It was beyond } \\
\text { my control." (Tightrope Walk) }\end{array}$ \\
\hline & $\begin{array}{l}\text { Lack of a sense of } \\
\text { unity with virtual } \\
\text { character }\end{array}$ & $\begin{array}{l}\text { "I sensed a lack of unity between my movement and that of the virtual character, so I got } \\
\text { a bad score; this made me lose interest in the game." (Ski Slalom) }\end{array}$ \\
\hline & Unclear goals & "I did not find any reason for me to do this exercise or to have any specific goals." (Warrior) \\
\hline
\end{tabular}

of Self-Consciousness, the mean score was significantly higher than the norm value for dance $(p<0.001)$; for Transformation of Time, the mean score was significantly higher than the norm value for dance $(p<0.05)$; and for Autotelic Experience, the mean score was significantly higher than the norm value for sports $(p<0.001)$, exercise activity $(p<$ $0.05)$, and dance $(p<0.001)$ (Figure 4).

\section{Expectancy of Physical Improvement and Intention of Exercise Adherence}

In response to the question: "Do you think there will be any physical improvement with these exercises?" 24 of the 25 participants $(96 \%)$ responded "yes." In response to the question: "From what type of program do you expect physical improvement?," 18 participants (75\%) reported "both in training and game type," 6 participants $(25 \%)$ reported "only in training type," and no participants reported "only in game type." The majority (96\%) of par- ticipants said that they would like to use the NWFP in future rehabilitation treatment. One participant who responded "no" told the researcher verbally that it was because she did not like sports.

\section{DISCUSSION}

In this study, we explored the perspectives of knee surgery patients regarding VR-based rehabilitation and found that level of difficulty was the key determinant of immersion. This finding highlights the need for the use of a VR program with varied levels of difficulty and that takes into account the severity of the knee injury to best meet patient perspectives. In addition, levels of pain and physical dysfunction did not affect the flow experience, thus verifying the applicability of VR-based rehabilitation for patients following knee surgery. 

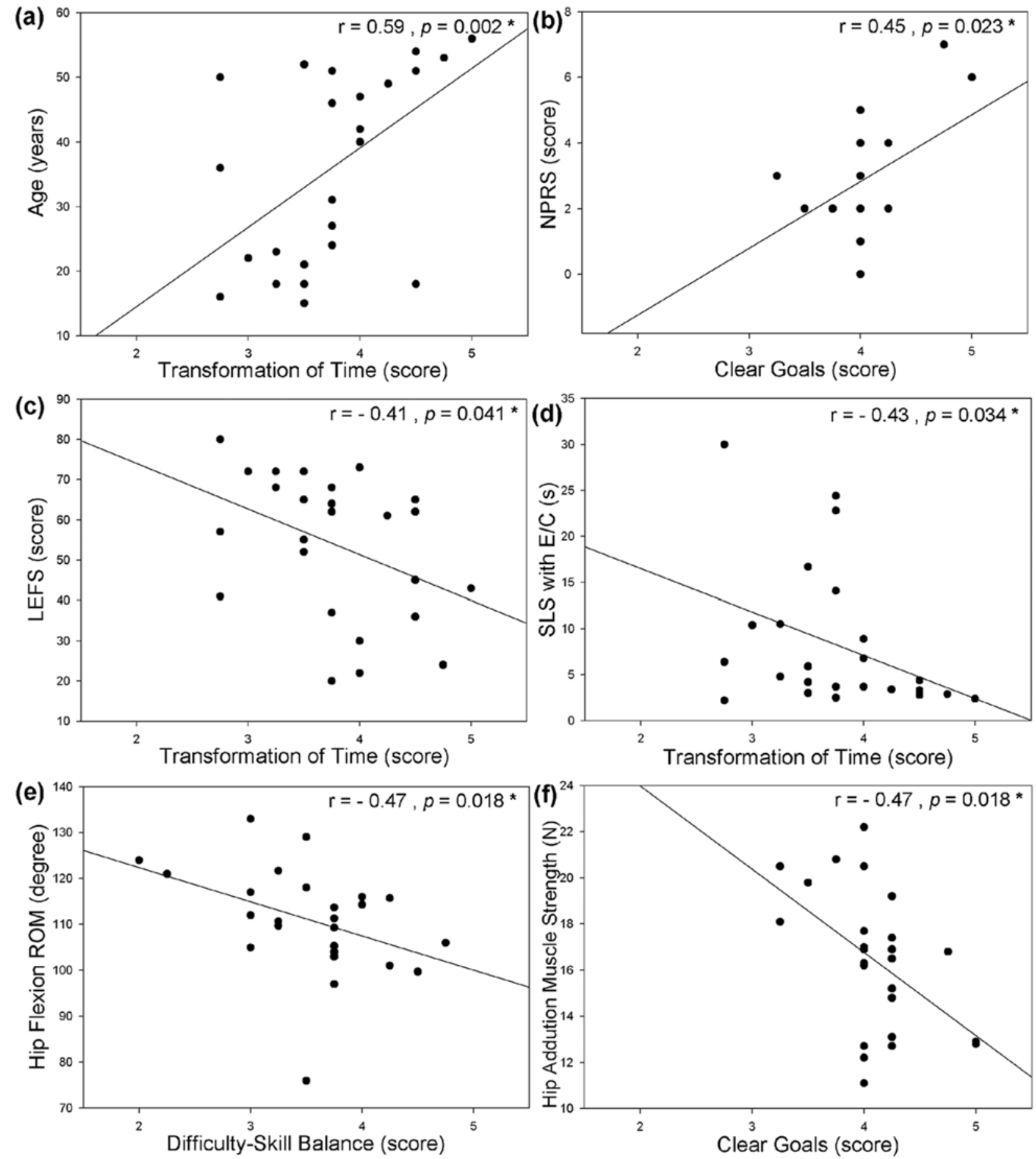

Figure 3.

(a)-(f) Relationships between participants' scores on Flow State Scale-2 (FSS-2) and physical dysfunction. Note: In each graph, $x$-axis represents participant's score on each dimension of FSS-2, and $y$-axis represents participant's age and degree of pain and physical dysfunction. Lines in scatter plots indicate direction and degree of correlation. Correlation coefficient $r \geq 0.04$ means fairly positive correlation. Correlation coefficient $r \leq-0.04$ means fairly negative correlation. *Significance was set at $p<0.05$. E/C $=$ eyes closed, LEFS = Lower Extremity Functional Scale, NPRS = numerical pain rating scale, ROM = range of motion, SLS = Single-Leg Stance. 


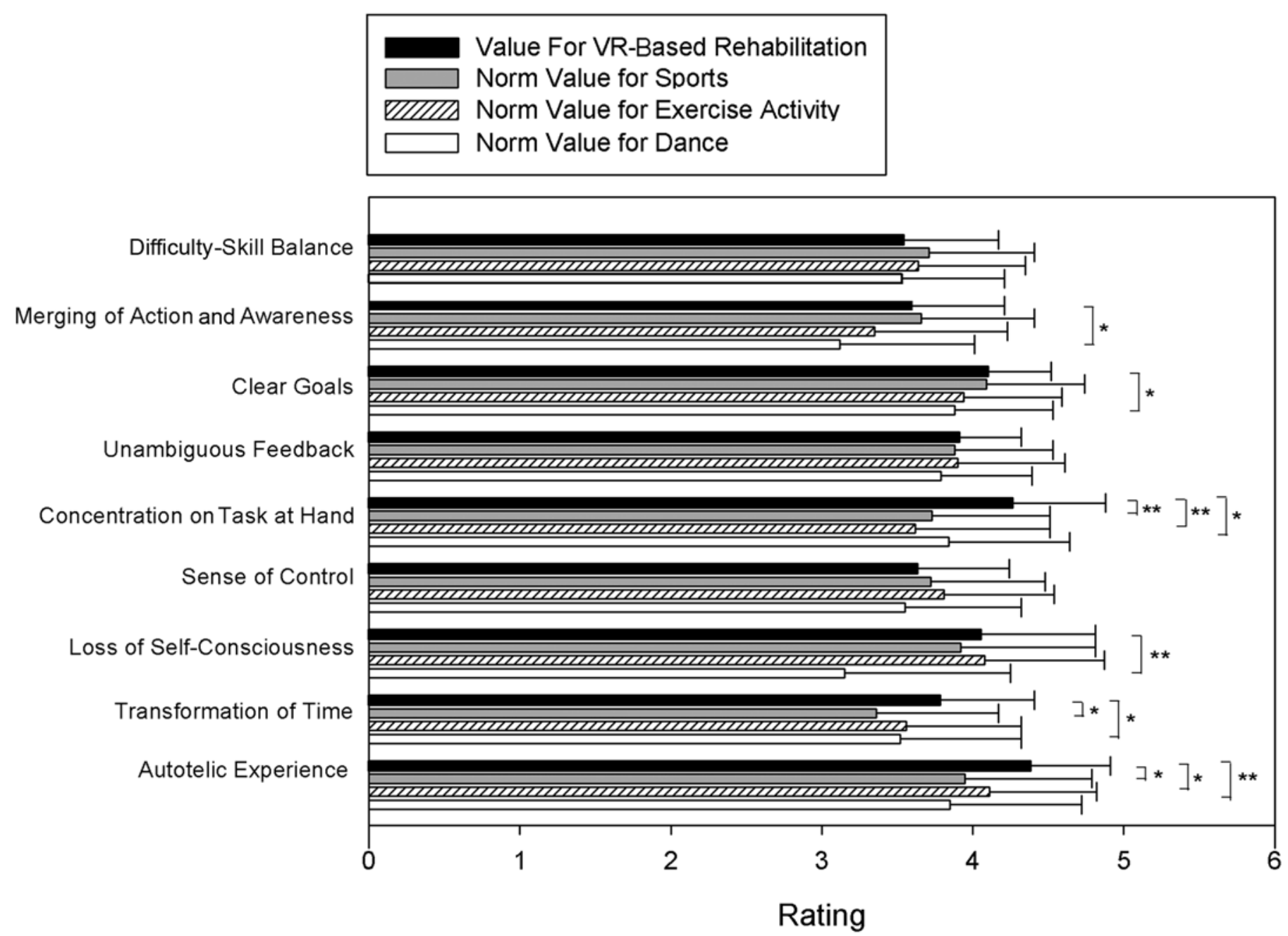

Figure 4.

Comparison of participants' mean scores of Flow State Scale-2 with norm values. Note: Norm values for sports $(n=700)$, exercise activity $(n=200)$, and dance $(n=80)$ in nondisabled subjects were adapted from Jackson and Marsh [26]. Values are mean and standard deviation. ${ }^{*} p<0.05,{ }^{* *} p<0.001$. VR $=$ virtual reality.

The qualitative analysis suggests that the balance between task difficulty and personal skill level is a necessary prerequisite for immersion: participants commonly mentioned "level of difficulty" as the reason for being the most and least immersed. "Good performance," "feeling of doing well," and "gradually increased difficulty" were reasons specifically stated that allowed participants to feel immersed the most. As a reason for being immersed the least, both "too high level of difficulty" and "too low level of difficulty" were stated. This finding is consistent with previous studies in older adults and patients with stroke. For example, Belchior et al. suggested that older adults' immersion during VR-based games could be adjusted to their skill levels [52]. Hale et al. reported that patients with stroke seemed to enjoy VR-based rehabilitation when they were equipped with suitable technology [21].

In contrast to our first hypothesis, quantitative analysis revealed that the flow experience was not influenced by the severity of the knee injury. Rather, in some dimensions of the FSS-2, participants with more severe pain or physical dysfunction tended to experience more positive feelings. These positive feelings might be due to the psychological rewards inherent in VR-based rehabilitation. For example, the NWFP could provide unrealistic adventures to participants, such as walking on a tight rope or sliding on an iceberg, without the dangers present in the 
real world. This sense of psychological reward might have been greater in participants with markedly impaired function because of the deeper frustration and discouragement that they might experience in the real world. This finding also implies that the difficulty level of the NWFP was more appropriate for participants with severe physical dysfunction. In other words, the level of difficulty of the NWFP might be relatively low for less impaired participants. This assumption is supported by a study by Graves et al., who reported a light-to-moderate general Rating of Perceived Exertion for the NWFP [53].

In contrast to our second hypothesis, the level of flow experience reported by patients during VR-based rehabilitation was higher than the published norm values for sports, physical activity, and dance in nondisabled participants. In particular, participants marked a significantly higher level of Concentration on the Task at Hand and Autotelic Experience than all three norm values. Autotelic Experience is an intrinsically rewarding experience involving a sense of deep enjoyment [26]. Hence, we could cautiously interpret this finding as suggesting that participants potentially found the NWFP to be more gratifying and would be more willing to participate in it than nondisabled participants are to take part in sports, exercise, or dance.

In addition, we found that the NWFP was an acceptable rehabilitation tool for participants: the mean value for participants' flow experience while using the NWFP was high (3.9 out of 5.0); the majority (96\%) said that there would be physical improvement after using the NWFP and that they would like to continue to use the NWFP for rehabilitation. In addition, among the majority (96\%) showing a high expectation of therapeutic effect, 76 percent of participants responded that there would be physical improvement "both in training and game type" and 24 percent of participants responded "only in training type," whereas no participants responded "only in game type." In contrast, 72 percent of participants chose balance games as the most immersive exercise. Therefore, both training and game types seem to be necessary, because of participants' different expectations from each type: the training type is more for therapeutic effects, whereas the game type is more for enjoyment or immersion.

\section{STUDY LIMITATIONS}

The number of participants was limited. Additional participants, especially in a quantitative study, may have led to a more homogeneous distribution. To supplement this limitation, however, a mixed-methods approach using both qualitative and quantitative methods was adopted in this study, which supports the contention that VR-based rehabilitation is feasible and acceptable for patients following knee surgery. The norm values of the FSS-2 compared with the FSS-2 scores of this study were not for patients following knee surgery. Even with this limitation, we could estimate the level of flow experience more clearly by such comparisons.

\section{CONCLUSIONS}

VR-based games are potentially acceptable as a motivational rehabilitation tool for patients after knee surgery, showing a high level of flow experience and high rate of expectation of therapeutic effect and intention of exercise adherence. However, to engage knee surgery patients fully, it might be necessary to use a VR program with varied levels of difficulty, taking into account the participants' pain severity and physical dysfunction. In addition, severe pain or physical dysfunction might act as an indication rather than a contraindication for rehabilitation using VR.

\section{ACKNOWLEDGMENTS}

\section{Author Contributions:}

Study concept and design: M. Lee, B. Yoon, D. Suh. Acquisition, analysis, and interpretation of data: M. Lee, D. Suh. Drafting of manuscript: M. Lee, J. Son.

Critical revision of manuscript for important intellectual content: J. Son, J. Kim.

Qualitative analysis: M. Lee, B. Yoon, D. Suh.

Quantitative analysis: M. Lee, J. Kim, S. Eun.

Obtained funding: B. Yoon, D. Suh.

Administrative, technical, or material support: B. Yoon, D. Suh, S. Eun. Study supervision: B. Yoon.

Financial Disclosures: The authors have declared that no competing interests exist.

Funding/Support: This material was based on work supported by the Korean National Rehabilitation Center, South Korea.

Additional Contributions: We thank the participants who willingly gave their time and ideas during the assessment and treatment. 
Institutional Review: This study was approved by Institutional Review Board of Korea University (KU-IRB-13-22-A-2). Written informed consent was obtained from all participants following the Declaration of Helsinki.

Participant Follow-Up: The authors plan to inform participants of the publication of this study.

\section{REFERENCES}

1. Sherry JL. Flow and media enjoyment. Commun Theory. 2004;14(4):328-47. http://dx.doi.org/10.1111/j.1468-2885.2004.tb00318.x

2. Kim J, Son J, Ko N, Yoon B. Unsupervised virtual realitybased exercise program improves hip muscle strength and balance control in older adults: A pilot study. Arch Phys Med Rehabil. 2013;94(5):937-43. [PMID:23262158] http://dx.doi.org/10.1016/j.apmr.2012.12.010

3. Deutsch JE, Borbely M, Filler J, Huhn K, GuarreraBowlby P. Use of a low-cost, commercially available gaming console (Wii) for rehabilitation of an adolescent with cerebral palsy. Phys Ther. 2008;88(10):1196-1207. [PMID:18689607]

http://dx.doi.org/10.2522/ptj.20080062

4. Saposnik G, Teasell R, Mamdani M, Hall J, McIlroy W, Cheung D, Thorpe KE, Cohen LG, Bayley M; Stroke Outcome Research Canada (SORCan) Working Group. Effectiveness of virtual reality using Wii gaming technology in stroke rehabilitation: A pilot randomized clinical trial and proof of principle. Stroke. 2010;41(7):1477-84. [PMID:20508185] http://dx.doi.org/10.1161/STROKEAHA.110.584979

5. Betker AL, Desai A, Nett C, Kapadia N, Szturm T. Gamebased exercises for dynamic short-sitting balance rehabilitation of people with chronic spinal cord and traumatic brain injuries. Phys Ther. 2007;87(10):1389-98.

[PMID:17712036]

http://dx.doi.org/10.2522/ptj.20060229

6. Saposnik G, Mamdani M, Bayley M, Thorpe KE, Hall J, Cohen LG, Teasell R; EVREST Steering Committee; EVREST Study Group for the Stroke Outcome Research Canada Working Group. Effectiveness of Virtual Reality Exercises in STroke Rehabilitation (EVREST): Rationale, design, and protocol of a pilot randomized clinical trial assessing the Wii gaming system. Int J Stroke. 2010;5(1): 47-51. [PMID:20088994] http://dx.doi.org/10.1111/j.1747-4949.2009.00404.x

7. Piqueras M, Marco E, Coll M, Escalada F, Ballester A, Cinca C, Belmonte R, Muniesa JM. Effectiveness of an interactive virtual telerehabilitation system in patients after total knee arthoplasty: A randomized controlled trial. J Rehabil Med. 2013;45(4):392-96. [PMID:23474735] http://dx.doi.org/10.2340/16501977-1119
8. Haik J, Tessone A, Nota A, Mendes D, Raz L, Goldan O, Regev E, Winkler E, Mor E, Orenstein A, Hollombe I. The use of video capture virtual reality in burn rehabilitation: The possibilities. J Burn Care Res. 2006;27(2):195-97. [PMID:16566564] http://dx.doi.org/10.1097/01.BCR.0000200890.34084.76

9. Das DA, Grimmer KA, Sparnon AL, McRae SE, Thomas $\mathrm{BH}$. The efficacy of playing a virtual reality game in modulating pain for children with acute burn injuries: A randomized controlled trial [ISRCTN87413556]. BMC Pediatr. 2005;5(1):1. [PMID:15745448] http://dx.doi.org/10.1186/1471-2431-5-1

10. Hoffman HG, Patterson DR, Carrougher GJ. Use of virtual reality for adjunctive treatment of adult burn pain during physical therapy: A controlled study. Clin J Pain. 2000; 16(3):244-50. [PMID:11014398] http://dx.doi.org/10.1097/00002508-200009000-00010

11. Fung V, Ho A, Shaffer J, Chung E, Gomez M. Use of Nintendo Wii Fit ${ }^{\mathrm{TM}}$ in the rehabilitation of outpatients following total knee replacement: A preliminary randomised controlled trial. Physiotherapy. 2012;98(3):183-88.

[PMID:22898573] http://dx.doi.org/10.1016/j.physio.2012.04.001

12. Merians AS, Jack D, Boian R, Tremaine M, Burdea GC, Adamovich SV, Recce M, Poizner H. Virtual realityaugmented rehabilitation for patients following stroke. Phys Ther. 2002;82(9):898-915. [PMID:12201804]

13. Brütsch K, Schuler T, Koenig A, Zimmerli L, Koeneke SM, Lünenburger L, Riener R, Jäncke L, Meyer-Heim A. Influence of virtual reality soccer game on walking performance in robotic assisted gait training for children. J Neuroeng Rehabil. 2010;7:15. [PMID:20412572]

http://dx.doi.org/10.1186/1743-0003-7-15

14. Frederick CM, Morrison C, Manning T. Motivation to participate, exercise affect, and outcome behaviors toward physical activity. Percept Mot Skills. 1996;82(2):691-701. [PMID:8724948] http://dx.doi.org/10.2466/pms.1996.82.2.691

15. Ryan RM, Frederick CM, Lepes D, Rubio N, Sheldon KM. Intrinsic motivation and exercise adherence. Int J Sport Psychol. 1997;28:335-54.

16. Lewis GN, Woods C, Rosie JA, McPherson KM. Virtual reality games for rehabilitation of people with stroke: Perspectives from the users. Disabil Rehabil Assist Technol. 2011;6(5):453-63. [PMID:21495917] http://dx.doi.org/10.3109/17483107.2011.574310

17. Sandlund M, Dock K, Häger CK, Waterworth EL. Motion interactive video games in home training for children with cerebral palsy: Parents' perceptions. Disabil Rehabil. 2012; 34(11):925-33. [PMID:22066685] http://dx.doi.org/10.3109/09638288.2011.626489 
18. Bryanton C, Bossé J, Brien M, McLean J, McCormick A, Sveistrup H. Feasibility, motivation, and selective motor control: Virtual reality compared to conventional home exercise in children with cerebral palsy. Cyberpsychol Behav. 2006;9(2):123-28. [PMID:16640463]

http://dx.doi.org/10.1089/cpb.2006.9.123

19. Yong Joo L, Soon Yin T, Xu D, Thia E, Pei Fen C, Kuah CW, Kong KH. A feasibility study using interactive commercial off-the-shelf computer gaming in upper limb rehabilitation in patients after stroke. J Rehabil Med. 2010; 42(5):437-41. [PMID:20544153] http://dx.doi.org/10.2340/16501977-0528

20. Rand D, Kizony R, Weiss PT. The Sony PlayStation II EyeToy: Low-cost virtual reality for use in rehabilitation. J Neurol Phys Ther. 2008;32(4):155-63. [PMID:19265756] http://dx.doi.org/10.1097/NPT.0b013e31818ee779

21. Hale LA, Satherley JA, McMillan NJ, Milosavljevic S, Hijmans JM, King MJ. Participant perceptions of use of CyWee $\mathrm{Z}$ as adjunct to rehabilitation of upper-limb function following stroke. J Rehabil Res Dev. 2012;49(4):623-34. [PMID:22773264] http://dx.doi.org/10.1682/JRRD.2001.04.0070

22. Woolf AD, Pfleger B. Burden of major musculoskeletal conditions. Bull World Health Organ. 2003;81(9):646-56. [PMID:14710506]

23. Badley EM, Rasooly I, Webster GK. Relative importance of musculoskeletal disorders as a cause of chronic health problems, disability, and health care utilization: Findings from the 1990 Ontario Health Survey. J Rheumatol. 1994; 21(3):505-14. [PMID:8006895]

24. Pisters MF, Veenhof C, Schellevis FG, Twisk JW, Dekker J, De Bakker DH. Exercise adherence improving long-term patient outcome in patients with osteoarthritis of the hip and/or knee. Arthritis Care Res (Hoboken). 2010;62(8): 1087-94. [PMID:20235201] http://dx.doi.org/10.1002/acr.20182

25. Csikszentmihalyi M. Flow: The psychology of optimal experience. New York (NY): Harper and Row; 1990.

26. Jackson SA, Marsh HW. Development and validation of a scale to measure optimal experience: The Flow State Scale. J Sport Exerc Psychol. 1996;18:17-35.

27. Jackson SA, Martin AJ, Eklund RC. Long and short measures of flow: The construct validity of the FSS-2, DFS-2, and new brief counterparts. J Sport Exerc Psychol. 2008; 30(5):561-87. [PMID:18971512]

28. Jackson SA, Eklund RC. Assessing flow in physical activity: The Flow State Scale-2 and Dispositional Flow Scale2. J Sport Exerc Psychol. 2002;24:133-50.

29. Bakker AB, Oerlemans W, Demerouti E, Slot BB, Ali DK. Flow and performance: A study among talented Dutch soccer players. Psychol Sport Exerc. 2011;12:442-50. http://dx.doi.org/10.1016/j.psychsport.2011.02.003
30. Thin AG, Hansen L, McEachen D. Flow experience and mood states while playing body movement-controlled video games. Games Cult. 2011;6:414-28.

http://dx.doi.org/10.1177/1555412011402677

31. Bronner S, Pinsker R, Noah JA. Energy cost and game flow of 5 exer-games in trained players. Am J Health Behav. 2013;37(3):369-80. [PMID:23985184] http://dx.doi.org/10.5993/AJHB.37.3.10

32. Greene JC, Caracelli VJ, Graham WF. Toward a conceptual framework for mixed-method evaluation designs. Educ Eval Policy Anal. 1989;11:255-74. http://dx.doi.org/10.3102/01623737011003255

33. Mortenson WB, Oliffe JL. Mixed methods research in occupational therapy: A survey and critique. OTJR (Thorofare N J). 2009;29:14-23.

34. Crum RM, Anthony JC, Bassett SS, Folstein MF. Population-based norms for the Mini-Mental State Examination by age and educational level. JAMA. 1993;269(18):2386-91. [PMID:8479064] http://dx.doi.org/10.1001/jama.1993.03500180078038

35. Clark RA, Bryant AL, Pua Y, McCrory P, Bennell K, Hunt M. Validity and reliability of the Nintendo Wii Balance Board for assessment of standing balance. Gait Posture. 2010;31(3):307-10. [PMID:20005112] http://dx.doi.org/10.1016/j.gaitpost.2009.11.012

36. Hjermstad MJ, Fayers PM, Haugen DF, Caraceni A, Hanks GW, Loge JH, Fainsinger R, Aass N, Kaasa S; European Palliative Care Research Collaborative (EPCRC). Studies comparing Numerical Rating Scales, Verbal Rating Scales, and Visual Analogue Scales for assessment of pain intensity in adults: A systematic literature review. J Pain Symptom Manage. 2011;41(6):1073-93. [PMID:21621130] http://dx.doi.org/10.1016/j.jpainsymman.2010.08.016

37. Binkley JM, Stratford PW, Lott SA, Riddle DL; North American Orthopaedic Rehabilitation Research Network. The Lower Extremity Functional Scale (LEFS): Scale development, measurement properties, and clinical application. Phys Ther. 1999;79(4):371-83. [PMID:10201543]

38. Powell LE, Myers AM. The Activities-specific Balance Confidence (ABC) Scale. J Gerontol A Biol Sci Med Sci. 1995;50A(1):M28-34. [PMID:7814786] http://dx.doi.org/10.1093/gerona/50A.1.M28

39. Michikawa T, Nishiwaki Y, Takebayashi T, Toyama Y. One-leg standing test for elderly populations. J Orthop Sci. 2009;14(5):675-85. [PMID:19802686] http://dx.doi.org/10.1007/s00776-009-1371-6

40. Franchignoni F, Tesio L, Martino MT, Ricupero C. Reliability of four simple, quantitative tests of balance and mobility in healthy elderly females. Aging (Milano). 1998; 10(1):26-31. [PMID:9589748]

41. Kolber MJ, Vega F, Widmayer K, Cheng M-S. The reliability and minimal detectable change of shoulder mobility 
measurements using a digital inclinometer. Physiother Theory Pract. 2011;27(2):176-84. [PMID:20690872]

http://dx.doi.org/10.3109/09593985.2010.481011

42. Maenhout A, Van Eessel V, Van Dyck L, Vanraes A, Cools A. Quantifying acromiohumeral distance in overhead athletes with glenohumeral internal rotation loss and the influence of a stretching program. Am J Sports Med. 2012; 40(9):2105-12. [PMID:22869627] http://dx.doi.org/10.1177/0363546512454530

43. Norkin CC. Measurement of joint motion: A guide to goniometry. 4th ed. Philadelphia (PA): F.A. Davis; 2009.

44. van den Beld WA, van der Sanden GA, Sengers RC, Verbeek AL, Gabreëls FJ. Validity and reproducibility of handheld dynamometry in children aged 4-11 years. J Rehabil Med. 2006;38(1):57-64. [PMID:16548089] http://dx.doi.org/10.1080/16501970510044043

45. Kelln BM, McKeon PO, Gontkof LM, Hertel J. Hand-held dynamometry: Reliability of lower extremity muscle testing in healthy, physically active, young adults. J Sport Rehabil. 2008;17(2):160-70. [PMID:18515915]

46. Hislop H, Avers D, Brown M. Daniels and Worthingham's muscle testing: Techniques of manual examination and performance testing. 9th ed. Amsterdam (the Netherlands): Saunders, Elsevier; 2013.

47. Shin S. A study of the influences of dance majors' flow experience on their performance satisfaction [master's thesis]. [Seoul (South Korea)]: Ewha Womans University; 2008.

48. Hsieh HF, Shannon SE. Three approaches to qualitative content analysis. Qual Health Res. 2005;15(9):1277-88. [PMID:16204405] http://dx.doi.org/10.1177/1049732305276687
49. Patton MQ. Qualitative evaluation and research methods. 2nd ed. Thousand Oaks (CA): Sage Publications; 1990.

50. Krefting L. Rigor in qualitative research: The assessment of trustworthiness. Am J Occup Ther. 1991;45(3):214-22. [PMID:2031523] http://dx.doi.org/10.5014/ajot.45.3.214

51. Thomas DR. A general inductive approach for analyzing qualitative evaluation data. Am J Eval. 2006;27:237-46. http://dx.doi.org/10.1177/1098214005283748

52. Belchior P, Marsiske M, Sisco S, Yam A, Mann W. Older adults' engagement with a video game training program. Act Adapt Aging. 2012;36(4):269-79. [PMID:23504652] http://dx.doi.org/10.1080/01924788.2012.702307

53. Graves LE, Ridgers ND, Williams K, Stratton G, Atkinson G, Cable NT. The physiological cost and enjoyment of Wii Fit in adolescents, young adults, and older adults. J Phys Act Health. 2010;7(3):393-401. [PMID:20551497]

Submitted for publication July 15, 2014. Accepted in revised form July 15, 2015.

This article and any supplementary material should be cited as follows:

Lee M, Suh D, Son J, Kim J, Eun S, Yoon B. Patient perspectives on virtual reality-based rehabilitation after knee surgery: Importance of level of difficulty. J Rehabil Res Dev. 2016;53(2):239-52.

http://dx.doi.org/10.1682/JRRD.2014.07.0164

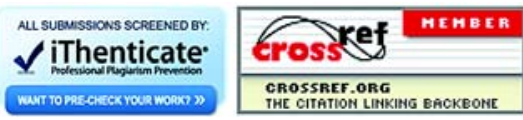

